\title{
AVALIAÇÃO DO TEMPO DE INDUÇÃO DE RESISTÊNCIA AO PULGÃO-VERDE Schizaphis graminum (ROND.) (HEMIPTERA: APHIDIDAE) EM PLANTAS DE TRIGO TRATADAS COM ÁCIDO SILÍCICO
}

\author{
Camila Cramer Filgueiras ${ }^{1}$, Jair Campos Moraes $^{2}$, Fabíola Alves Santos ${ }^{3}$, Amália Torrezan \\ Lopes $^{4}$ \\ 1 Instituto de Ciências Agrárias, Universidade Federal Rural da Amazônia, UFRA, Belém/ PA. Email: \\ camilacramer@hotmail.com \\ ${ }^{2}$ Departamento de Entomologia, Universidade Federal de Lavras, UFLA, Lavras/ MG \\ ${ }^{3}$ Departamento de Entomologia, Universidade Federal de Lavras, UFLA, Lavras/ MG \\ ${ }^{4}$ Departamento de Entomologia, FCAV-UNESP, Jaboticabal/SP
}

\section{RESUMO}

O trigo é um dos cereais mais cultivados em todo o mundo, sendo o pulgão-verde importante inseto-praga dessa cultura. Métodos de controle como aplicação de silício, que aumentam a resistência das plantas ao ataque de insetos praga têm sido cada vez mais pesquisados. Este trabalho objetivou monitorar o tempo entre a aplicação do ácido silícico em plantas de trigo e a indução de resistência ao pulgão. $\mathrm{O}$ experimento foi conduzido em casa de vegetação e adotou-se o DBC, em esquema fatorial 2 (com e sem silício) x 5 (avaliações após 24, 48, 72, 96 e 120 horas da aplicação de silício), com 8 repetições. Os tratamentos com $\mathrm{Si}$ consistiram na aplicação, em drench, de $50 \mathrm{~mL} / \mathrm{vaso}$ de solução de ácido silícico a $1 \%$, equivalendo a $4 \mathrm{t}$ de $\mathrm{SiO}_{2} /$ ha. Foi realizado teste de preferência, com chance de escolha. Utilizaram-se gaiolas cilíndricas com dois orifícios, nos quais foram colocadas uma folha da planta tratada com Si (sem ser destacada da planta) e uma folha da outra planta não tratada com $\mathrm{Si}$ (testemunha). Cinco pulgões adultos foram colocados em cada orifício da gaiola e avaliados após 24 horas. $\mathrm{O}$ ácido silícico induziu resistência ao pulgão-verde 72 horas após a sua aplicação em plantas de trigo.

Palavras-chave: Insecta, resistência induzida, manejo integrado de pragas

\section{EVALUATION OF THE TIME OF INDUCED RESISTANCE TO THE GREENBUG Schizaphis graminum (ROND.) (HEMIPTERA: APHIDIDAE) ON SILICIC ACID- TREATED WHEAT PLANTS}

\section{ABSTRACT}

The wheat is one of the most cultivated grains in the world, being the greenbug a very important insect pest in this culture and methods which control the pest with silicic have been more studied. This study aimed to track the time between the application of silicic acid in wheat plants and the resistance induction to aphids. The tests were conducted in greenhouse, and used the DBC, in a factorial scheme 2 (with and without silicic) x 5 (ratings after 24, 48, 72, 96 and 120 hours from silicon application), with 8 replications. The treatments consisted in drench application with Silicic of $50 \mathrm{~mL}$ of silicic acid solution to $1 \%$ each pot that equals $4 \mathrm{t}$ of $\mathrm{SiO}_{2} / \mathrm{ha}$. Free choice test was set. One used cylindrical cages with two holes, where one leave of plant 
treated with silicic and one leave without treatment of silicic were set. Five adult aphids were placed in each cage hole and assessed after 24 hours. The silicic acid induced the resistance to the greenbug after 72 hours of its application in wheat plants.

Key words: Insecta, induced resistance, integrated pest management.

\section{INTRODUÇÃO}

O trigo tem grande importância no consumo humano, considerado muitas vezes como "o mais nobre dos cereais" devido ao seu alto valor energético, rico em carboidratos e com boas quantidades de proteína (Maia, 1996). No inicio, década de 80 , incentivada pela política do governo, a triticultura brasileira teve uma forte expansão, com a privatização da comercialização nacional e a abertura do mercado. Apesar disso, no início da década de 90, houve prejuízos no setor, que não estava preparado para competir. A produção mundial de trigo gira em torno de 590 milhões de toneladas/ano, com consumo de 615 toneladas/ano, sendo necessário um estoque de no mínimo 128 milhões de toneladas para suprir o mercado. A produção brasileira que na safra 06/07 chegou próximo a 3,4 milhões de toneladas, não foi capaz de abastecer o mercado interno, cujo consumo gira em torno de 10,3 milhões de toneladas, tornando o País altamente dependente do mercado externo, sendo um grande importador principalmente da Argentina, Estados Unidos e Canadá, nossos principais fornecedores (Agrianual, 2007).

O pulgão-verde Schizaphis graminum (Rondani, 1852) (Hemiptera: Aphididae) tem sido relatado em mais de 60 espécies da família Poaceae, sendo as maiores infestações verificadas em sorgo, trigo, cevada, aveia e centeio (Daniels, 1960). Este inseto e capaz de produzir 3 a 4 gerações por mês, sendo a temperatura ótima para reprodução entre 21 e $24^{\circ} \mathrm{C}$, podendo também reproduzir-se na faixa de 10 a $33^{\circ} \mathrm{C}$. Possui 4 ínstares ninfais quando em condições adequadas, e podem ocorrer até 20 gerações durante um ano agrícola (Pfadt, 1978). As injúrias e danos causados pelo pulgão-verde atingem a planta desde a fase de plântula até o enchimento dos grãos, podendo levá-la à morte (Silva et al., 1996). $\mathrm{O}$ pulgão-verde causa danos diretos e indiretos, danificando as plantas pela grande quantidade de seiva extraída, causando limitação de água e nutrientes, e injetando toxinas durante a alimentação, as quais causam clorose e necrose do tecido foliar. Além dos danos diretos, o pulgão pode transmitir viroses, predispor a planta a doenças e afetar a qualidade dos grãos (Berger et al., 1983; Cruz, 1986; Cruz et al., 1998).

O controle químico é predominante no manejo do pulgão-verde e recomendado quando a infestação atingir $10 \%$ das plantas infestadas durante a fase vegetativa ou ultrapassar dez pulgões por espiga até a fase de grão em massa mole (Silva et al., 1996). $\mathrm{Na}$ maioria das situações são feitas duas aplicações de inseticidas por safra, podendo, em muitos casos, ser feitas três a quatro aplicações para o controle efetivo dos pulgões, gerando um desequilíbrio ecológico. Dessa forma, a produção de trigo ainda é dependente do uso de inseticidas, onerando o custo de produção (Salvadori, 1999).

O silício é encontrado na solução do solo, como ácido silícico $\left(\mathrm{H}_{4} \mathrm{SiO}_{4}\right)$, sendo assim absorvido de forma passiva pelo sistema radicular juntamente com a água ou de forma ativa, via foliar (MA et al., 2001). Quando absorvido, grande parte do silício é depositada na parede celular nas células da epiderme (JARVIS, 1987). Baseado na 
quantidade de silício acumulado nos tecidos vegetais, as plantas podem ser classificadas em acumuladoras, intermediárias e não acumuladoras (Ma et al., 2001), sendo o trigo uma espécie acumuladora. Apesar de ser o segundo elemento mais abundante na crosta terrestre, os solos tropicais muitas vezes apresentam baixa capacidade de fornecimento de silício às plantas, pois são extremamente intemperizados, ácidos, cultivados sucessivamente e com alto potencial de lixiviação (Brady, 1992).

O silício é um nutriente vegetal que não preenche todos os critérios a partir dos quais um elemento químico é considerado essencial para as plantas e, assim, é considerado como elemento benéfico ou útil às plantas. Dentre as respostas ao fornecimento de silício, destacam-se a diminuição do acamamento, o aumento da resistência ao estresse hídrico, ganhos de produtividade e aumento da resistência das plantas ao ataque de pragas e doenças (Nojosa et al., 2006).

A resistência de plantas a insetos é uma importante prática de manejo de pragas que se deve a fatores intrínsecos e genéticos das plantas. É o resultado da ativação de diferentes vias de defesa da planta que podem provocar mudanças tanto na qualidade como na quantidade de compostos do metabolismo secundário e de proteínas de defesa, acúmulo de espécies reativas de oxigênio, como também modificações na qualidade do alimento e reforço das barreiras estruturais da planta. Esses diferentes tipos de respostas podem ocorrer separadamente ou em combinações distintas, dependendo do agente indutor e da planta em questão. Muitos estudos de resistência de plantas a insetos monitoram a concentração de compostos de defesa das plantas ou a atividade de enzimas que participam de sua síntese (Vendramim \& França, 2006).

Para que haja o desencadeamento do processo de indução de resistência é necessário que haja um indutor ou elicitor, que pode ser de natureza biótica ou abiótica (Dixon et al., 1994). Estudos têm apontado o silício como indutor de resistência a insetos (Gomes et al., 2005; Correa et al., 2005) e a patógenos (Liang et al., 2005; Ghanmi et al., 2004). Entretanto, a proteção que este elemento confere às plantas também pode ser devida ao seu acúmulo e polimerização na parede celular, que aumenta a rigidez dos tecidos e atua como uma barreira mecânica à penetração e à alimentação dos insetos (Yoshida et al., 1962; Goussain et al., 2002, 2006). O uso agrícola de elicitores, que seja capaz de reduzir o ataque de insetos-praga, deve estar sujeito a uma criteriosa e cuidadosa análise custo/benefício, a redução no número de aplicações de produtos fitossanitários na cultura certamente proporcionaria redução de custos de produção e benefícios ambientais (Gomes, 2007).

O presente trabalho teve como objetivo monitorar o tempo entre a aplicação do ácido silícico em plantas de trigo e a indução de resistência ao pulgão.

\section{MATERIAL E MÉTODOS}

O experimento foi conduzido no Laboratório de Resistência de Plantas a Insetos e em casa-de-vegetação do Departamento de Entomologia da Universidade Federal de Lavras, no período de agosto/2006 a julho/2007.

Plantas de trigo: em casa de vegetação foram semeadas quatro sementes de trigo, cv Embrapa 22, em vasos de 250 gramas utilizando PLANTMAX como substrato. O desbaste, feito com tesoura de poda para evitar revolvimento do substrato e como consequiência danos nas plantas, foi realizado antes da aplicação da solução de ácido silícico, deixando-se duas plantas por vaso.

Solução de ácido silício: a solução a $1 \%$ de $\mathrm{SiO}_{2}$ foi obtida pela diluição de 10 gramas de acido silícico em 1 litro de água e, posteriormente armazenada em recipiente de 
dois litros, vedada e em local fresco sem incidência de luz. A dosagem utilizada foi de $50 \mathrm{~mL}$ por vaso, equivalendo a 4 toneladas de $\mathrm{SiO}_{2}$ por hectare. A aplicação da solução, realizada via drench no caule, próximo ao solo, feita após 30 dias do plantio.

Tratos culturais: foram feitas irrigações diárias, direto no substrato, sem contato direto com as folhas das plantas.

Criação de pulgões: o pulgão-verde foi mantido em seções foliares de sorgo, em copos plásticos de $50 \mathrm{~mL}$ com água e mantidas eretas com auxilio de círculos de isopor, colocados em câmara climatizada a
$25 \pm 2{ }^{\circ}$ C, U.R. de $70 \%$ e fotofase de 14 horas. A cada dois dias, os copinhos foram lavados, a água e as folhas de sorgo trocadas, sendo os pulgões transferidos com auxilio de um pincel.

Gaiolas: foram confeccionadas gaiolas de acrílico, na forma cilíndrica com cerca de $1 \mathrm{~cm}$ de altura e $10 \mathrm{~cm}$ de diâmetro, compostas de dois orifícios circulares e grampos para melhor fixação nas folhas das plantas. Entre os grampos e a gaiola colocou-se uma espuma para evitar ferimento nas folhas.

Tratamentos:

- T1: sem aplicação de Si e avaliação após 24 horas;

- T2: com aplicação de Si e avaliação após 24 horas;

- T3: sem aplicação de Si e avaliação após 48 horas;

- T4: com aplicação de Si e avaliação após 48 horas;

- T5: sem aplicação de Si e avaliação após 72 horas;

- T6: com aplicação de Si e avaliação após 72 horas;

- T7: sem aplicação de Si e avaliação após 96 horas;

- T8: com aplicação de Si e avaliação após 96 horas;

- T9: sem aplicação de Si e avaliação após 120 horas;

- T10: com aplicação de Si e avaliação após 120 horas.

Montagem do teste de preferência com chance de escolha: uma folha de cada planta tratada com silício (sem ser destacada da planta) foi colocada em um dos orifícios da gaiola e uma folha da outra planta não tratada com silício (testemunha) em outro orifício. Cinco pulgões adultos foram colocados em cada orifício da gaiola, totalizando 10 pulgões. Após as infestações as gaiolas foram tampadas com tecido tipo organza. Para cada gaiola foram utilizados dois vasos que após a avaliação foram descartados. As avaliações foram realizadas 24, 48, 72, 96 e 120 horas após aplicação da solução de ácido silícico e a contagem de adultos e ninfas presentes sobre as folhas dos respectivos tratamentos após 24 horas da liberação dos insetos.

Análise Estatística: adotou-se o delineamento em blocos casualizados, em esquema fatorial 2 (com e sem silício) x 5 (avaliações após 24, 48, 72, 96 e 120 horas da aplicação de silício), com 8 repetições. Os dados foram transformados em $\sqrt{X+0,5}$ antes da análise estatística e as médias comparadas pelo teste Scott-Knott, a 5\% de significância, com auxílio do programa estatístico SISVAR. 


\section{RESULTADOS E DISCUSSÃO}

Com relação ao número de pulgões adultos presentes nas folhas de trigo, observa-se efeito do silício 72 horas após a sua aplicação. Nas demais horas avaliadas não ocorreram diferenças entre as plantas adubadas e não-adubadas com silício (Tabela 1). Verificou-se que o efeito do silício na indução de resistência ao pulgãoverde pode ocorrer três dias após a sua aplicação. Entretanto, devido a não manutenção dessa resistência após este período, novas pesquisas serão necessárias, principalmente em relação ao tempo de exposição dos insetos as plantas, que de acordo com Cruz et al., (1998) deve ser de pelo menos 72 horas.

Tabela 1. Número de adultos do pulgão Schizaphis graminum presentes nas folhas de trigo em função do tempo de aplicação de silício (Si).

\begin{tabular}{lcc}
\hline Tempo após aplicação & Com Si* & $\mathrm{Sem} \mathrm{Si}^{*}$ \\
\hline 24 horas & $5,1 \mathrm{~A}$ & $4,7 \mathrm{~A}$ \\
48 horas & $4,5 \mathrm{~A}$ & $5,0 \mathrm{~A}$ \\
72 horas & $4,0 \mathrm{~B}$ & $5,4 \mathrm{~A}$ \\
96 horas & $5,1 \mathrm{~A}$ & $4,9 \mathrm{~A}$ \\
120 horas & $4,6 \mathrm{~A}$ & $5,1 \mathrm{~A}$ \\
\hline CV $(\%)=17,6$ & \\
\hline
\end{tabular}

Em relação ao número de ninfas presentes nas folhas de trigo, não houve interação entre os tratamentos, porém, houve redução de cerca de $30 \%$ no número de ninfas nas plantas adubadas com silício (Tabela 2). Costa e Moraes (2006) também observaram diminuição no número de ninfas de $S$. graminum, em cerca de $80 \%$, em plantas de trigo adubadas com silício. Gomes et al. (2005) verificaram a diminuição da taxa de crescimento da população de $S$. graminum em plantas de trigo adubadas com silício. Em estudo do efeito do silício na cultura da batata controlando o pulgão $M$. persicae, observase também menor número de ninfas nas plantas tratadas com silício (Gomes et al., 2008).
Esta redução no número de ninfas pode ser devido ao efeito do silício na fecundidade das fêmeas e/ou na mortalidade direta destas. A qualidade da planta hospedeira pode afetar diretamente a fecundidade de insetos herbívoros em escala individual e populacional. Além disso, a qualidade nutricional está relacionada com os teores de carbono e nitrogênio presentes nas plantas e também com metabólitos secundários tóxicos ou deterrentes aos herbívoros (Bialczyk et al., 1999; Awmack \& Leather, 2002). Dessa forma, embora não analisado, o silício poderia ter atuado como indutor da síntese de compostos de defesa nas plantas de trigo ao pulgão-verde. 
Tabela 2. Número de ninfas do pulgão $S$. graminum presentes nas folhas de trigo em função do tempo de aplicação de silício (Si).

\begin{tabular}{lccc}
\hline Tempo após aplicação & Com Si & Sem Si & Média* \\
\hline 24 horas & 8,6 & 8,6 & $8,6 \mathrm{~b}$ \\
48 horas & 10,4 & 12,6 & $11,5 \mathrm{a}$ \\
72 horas & 9,2 & 17,1 & $13,2 \mathrm{a}$ \\
96 horas & 10,1 & 12,4 & $11,2 \mathrm{a}$ \\
120 horas & 8,6 & 11,2 & $9,9 \mathrm{~b}$ \\
\hline Média* & $9,4 \mathrm{~B}$ & $12,4 \mathrm{~A}$ & \\
\hline $\mathrm{CV}(\%)=37,0$ & & & \\
\hline
\end{tabular}

*Médias seguidas da mesma letra minúscula na coluna e mesma letra maiúscula na linha não diferem entre si pelo teste de $\operatorname{Scott} \& \operatorname{Knott}(\mathrm{P} \leq 0,05)$.

Em estudo realizado por Nascimento et al.(2010), observa-se o efeito negativo do silício na colonização de pulgões na cultura da batata. Resultado semelhante encontrado por Costa et al. (2007) estudando o pulgão $S$. graminum na cultura do trigo. Santos et al. (2009), relatam ainda o efeito negativo do silicio sobre as principais pragas da cultura do feijoeiro.

\section{CONCLUSÕES}

O ácido silícico aumentou a mortalidade dos pulgões e reduziu o número de ninfas.

\section{AGRADECIMENTOS}

Ao CNPq pela concessão de bolsas e à FAPEMIG pelo apoio financeiro ao projeto.

\section{REFERÊNCIAS BIBLIOGRÁFICAS}

AGRIANUAL 2007 - Anuário da Agricultura Brasileira. São Paulo: FNP Consultoria e Comércio. 2007. $516 \mathrm{p}$.

AWMACK, C. S.; LEATHER, S. R.2002. Host plant quality and fecundity in herbivorous insects. Annual Review of Entomology, v. 47, p.817-844.

BERGER, P. H.; TOLER, R. W.; HARRIS, K. F. 1983. Maize dwart mosaic virus transmission by greenbug biotypes. Plant Disease, St. Paul, v. 67, n. 5, p. 496-497.

BIALCZYK, J.; LECHOWSKI, Z.; LIBIK, A. 1999. The protective action of tannins against glasshouse whitefly in tomato seedlings. Journal of Agricultural Science, v. 133, p. 197201.

BRADY, N. C. 1992. The nature and properties of soils. 10. ed. New York: Macmillan, $750 \mathrm{p}$.

CORREA, R. S. B.; MORAES, J. C.; AUAD, A. M.; CARVALHO, G. A. 2005. Silicon and acibenzolar-Smethyl as resistance inducers in cucumber, against the whietfly Bemisia tabaci (Gennadius) (Hemiptera: Aleyrodidae) biotype B. Neotropical Entomology, v. 34, n. 3, p. 429-433.

COSTA, R. R.; MORAES, J. C. 2006. Efeitos do ácido silícico e do acibenzolar-s-methyl sobre Schizaphis graminum (Rondani) (Hemiptera: Aphididae) em plantas de trigo. Neotropical Entomology, Londrina, 
PR, v. 35, n. 6, p.834-839.

COSTA,R.R.; MORAES, J.C.; ANTUNES, C.S. 2007. Resistência induzida em trigo ao pulgão Schizaphis graminum (Rondani,1852)(Hemiptera:Aphididae ) por silício e acibenzolar-s-methyl. Ciência e Agrotecnologia, Lavras, v.31, n.2, p.393-397.

CRUZ, I. Resistência de genótipos de sorgo ao pulgão-verde Schizphis graminum (Rondani, 1852) (Homoptera: Aphididae). 1986. 222 p. Tese. (Doutorado em Entomologia) - Escola Superior de Agricultura Luiz de Queiroz, Piracicaca, SP.

CRUZ, I.; VENDRAMIN, J. D.; OLIVEIRA,A. C. 1998.Determinação do período de avaliação de nãopreferência de sorgo ao pulgão-verde, Schizaphis graminum (Rond.) (Homoptera: Aphididae). Anais da Sociedade Entomológica do Brasil, Piracicaba, v. 27, n. 2, p. 299-302.

DANIELS, N. E. 1960.. Evidence of the over summering of the greenbug in the Texas Panhandle. Journal of Economic Entomology, Lanham, v. 53, n. 3, p. 454-455.

DIXON, R. A.; HARRISON, M. J.; LAMB, C. J. 1994.Early events in the activation of plant defense responses. Annual Review of Phytopathology, Palo Alto, v.32, p.479-501.

GHANMI, D.; McNALLY, D. J.; BENHAMOU, N.; MENZIES, J. G.; BÉLANGER, R.R.2004.. Powdery mildew of Arabidopsis thaliana: a pathosystem for exploring the role of silicon in plant-microbe interactions. Physiological and Molecular Plant Pathology, v. 64, p. 189-199.

GOMES, F. B. 2007. Influência do silício na indução de resistência a Myzus persicae(Sulzer)

(Hemiptera:Aphididae) e na proteção de plantas de batata inglesa cultivadas em sistema orgânico. Tese (Doutorado)Universidade Federal de Lavras, UFLA, Lavras.

GOMES, F. B.; MORAES, J. C.; SANTOS, C. D.; GOUSSAIN, M. M.2005.. Resistance induction in wheat plants by silicon and aphids. Scientia Agricola, Piracicaba, v. 62, n. 6, p. 547-551.

GOMES, F.B.; MORAES, J.C.; SANTOS, C.D.; ANTUNES, C.S. 2008.Uso de silício como indutor de resistência em batata a Myzus persicae (Sulzer)(Hemiptera:Aphididae).

Neotropical Entomology, Londrina, v.37, n.2, p.185-190.

GOUSSAIN, M. M. 2006. Interação trigo silício - inseticida na biologia e no comportamento de prova do pulgãoverde Schizaphis graminum (Rondani) (Hemiptera: Aphididae) monitorado pela técnica Electrical Penetration Graphs (EG). 59 f. Tese (Doutorado) - Universidade Federal de Lavras, UFLA, Lavras.

GOUSSAIN, M. M.; MORAES, J. C.; CARVALHO, J. G.; NOGUEIRA, N. L.; ROSSI, M. L. 2002. Efeito da aplicação de silício em plantas de milho no desenvolvimento biológico da lagarta do cartucho Spodoptera frugiperda ( J. E. Smith) (Lepidoptera: Noctuidae). Neotropical Entomology, v. 31, n. 2, p. 305-310..

JARVIS, S. C. 1987.The uptake and transport of silicon by perennial ryegrass and wheat. Plant soil, v. 97, p. 429-437.

LIANG, Y. C.; SUN, W. C.; SI, J.; RÖMHELD, V. 2005.. Effects of foliar- and root- applied silicon on the enhancement of induced resistance to powdery mildew in Cucumis sativus. Plant Pathology, v. 54, p. 678-685.

MA, J. F.; MIYAKE, Y.; TAKAHASHI, E. 2001. Silicon as a beneficial element for crop lants. In: DATNOFF, L. E.; 
SNYDER, G. H.; KORNDÖRFER, G. $\mathrm{H}$. (Ed) Silicon in agriculture. The Netherlands: Elsevier Science. 403 p.

MAIA, S. F. 1996. Competitividade da produção de trigo do Paraná. 109 p. Dissertação (Mestrado em Economia Rural) - Universidade Federal de Viçosa, Viçosa, MG.

NASCIMENTO, A.M.; ASSIS, F.A.; MORAES, J.C.; SILVA, V.F.; PEIXOTO, M.L. 2010.Indutores de resistência sobre Myzus persicae (Sulzer) em batateira. Revista de Agricultura, v. 85, n.1, p.21-27.

NOJOSA , G. B. A.; RESENDE, M .L. V.; RESENDE, A. V. 2006. Uso de fosfitos e silicatos na indução de resistência. In: CAVALCANTI, L. S. et al.; (Ed.) Indução de resistência em plantas a patógenos e insetos. Piracicaba: FEALQ, $263 \mathrm{p}$.

PFADT, R. E. Insect pest of small grains. In: PFADT, R. E.1978.. Fundamentals of applied entomology. 3. ed. New York: Macmillan. p. 267-301.

SALVADORI, J. R. 1999 Controle biológico de pulgões de trigo: o sucesso que perdura. Revista Plantio Direto, Passo Fundo, n. 46, p. 25-31..

SANTOS, F.A.; FILGUEIRAS, C.C.; MORAES, J.C. 2009.Efeito do silício na ocorrência de insetos-praga e no desenvolvimento inicial do feijoeiro (Phaseolus vulgaris L.). Revista de Agricultura, v.84, n.3, p. 185-193.

SILVA, D. B.; GUERRA, A. F.; REIN, T. A.; ANJOS, J. R.; ALVES, R. T.; RODRIGUES, G. C.; SILVA, I. A. C. 1996. Trigo para o abastecimento familiar: do plantio à mês. Brasília: Embrapa- SPI, Planaltina: Embrapa: CPAC, 176p..

VENDRAMIM, J. D.; FRANÇA, S. C. 2006 Indução de resistência a insetos. In: CAVALCANTI, L. S.; PIERO, R. M.; CIA, P.; In: CAVALCANTI, L. S. et al. (Ed.) Indução de resistência em plantas a patógenos $\mathrm{e}$ insetos. Piracicaba: FEALQ.. 263p.

YOSHIDA, S.; OHNISHI, Y.; KITAGISHI, K. 1962.Histochemistry of silicon in rice plant. Soil Science and Plant Nutrition. Tokyo, v.8, p.107-111. 